\title{
O discurso sobre a terra italiana nas Geórgicas de Virgílio
}

The discourse about the Italian lands in Virgil's Georgics

Thaíse Pereira Bastos Silva Pio ${ }^{1}$ e-mail: thaisebastos@id.uff.br orcid: http://orcid.org/0000-0002-2555-5438

\section{DOI: http://dx.doi.org/10.25187/codex.v5i2.13467}

\section{Resumo:}

As Geórgicas (37-30 a. C.) constituem um poema sobre a vida rural e as diversas atividades agrícolas: o cultivo dos cereais, a arboricultura (em especial o cultivo da vinha), a criação dos rebanhos e a apicultura. Cada um dos quatro livros que compõem a obra descreve uma atividade específica, por meio do discurso eminentemente didático. Ao longo da obra, porém, notam-se diversas passagens digressivas, em que o poeta narra sobre outros temas, em geral, de cunho religioso, mitológico e filosófico. Uma destas passagens, conhecida como Laudes Italiae, versos 136 a 176 do canto II, constitui um verdadeiro hino de louvor às terras italianas. Intentamos verificar a relevância de alguns dos temas tratados nos referidos versos das Geórgicas, considerando, sobretudo, o contexto de produção da obra, e buscando compreender o seu significado dentro deste poema didático.

Palavras-chave: Século de Augusto; poesia didática; discurso poético; digressões

\begin{abstract}
:
The Georgics (37-30 BC) constitute a poem about rural life and various agricultural activities: the cultivation of cereals, arboriculture (especially the cultivation of the vine), herd rearing and beekeeping. Each of the four books that compose the work describes a specific activity, through didactic discourse eminently. Throughout the work, however, there are several digressive passages, in which the poet narrates about other themes, usually of a religious, mythological and philosophical nature. One of these passages, known as Laudes Italiae, verses 136 to 176 of the 2 nd book, constitutes a true hymn of praise to the Italian lands. We try to verify the relevance of some themes treated in the mentioned verses, considering, mainly, Georgics' context of production, and trying to understand its meaning within this didactic poem
\end{abstract}

Keywords: Augustus's age; didactic poetry; poetic discourse; digressions

\footnotetext{
${ }^{1}$ Doutora em Letras Clássicas pela Universidade Federal do Rio de Janeiro (Brasil). Professora Adjunta de Língua e Literatura Latina do Departamento de Letras Clássicas e Vernáculas do Instituto de Letras da Universidade Federal Fluminense (Brasil).
} 


\section{(3)}

No âmbito da literatura latina, a agricultura já havia sido tema tratado por autores predecessores, já nos séculos III e II a. C., a exemplo Catão e Varrão em seus respectivos tratados agronômicos De agri cultura e De re rustica. Nestas obras, já se podia vislumbrar também certo tom instrutivo e a finalidade de oferecer a um público restrito informações sobre os trabalhos campesinos. Entretanto, embora revelem intentos "professorais", tais textos possuem apenas tonalidades instrutivas, não se enquadrando, pois, no rol do gênero didático propriamente dito ${ }^{2}$.

Remete aos tempos mais primitivos da Grécia o fato de a poesia, a partir de tradição oral, estar vinculada ao ato didático-pedagógico, isto porque, por meio da memorização, e, posteriormente, com o advento da escrita, já como gênero literário, podia funcionar como veículo educador e meio difusor de ideologias, valores e de saberes diversos: científicos, filosóficos, religiosos etc.

Sobre a intrínseca relação entre educação e poesia, é importante notar que

o alcance formativo contido como dýnamis da poesia torna muito difícil sintetizar tudo o que ela atinge, dada a multiplicidade de aspectos que ela envolve, dentre eles, o ético, o político, o teológico, o social, o estético, o cultural e o pedagógico, em razão de a mesma resgatar e transmitir os costumes, as tradições, os valores, as crenças, os rituais, os jogos, as táticas de guerra, a educação, a administração social, política e militar da cidade, assim como as leis e as condutas pública e privada (SOUZA, 2007, p. 196).

A cultura helênica, desde sempre, revelou-se permeada pelos efeitos instrutivos da poesia na formação moral, ética, política e pedagógica do público. Temos Homero, Hesíodo e Platão como exemplos gregos de que as obras literárias possuíam elevado potencial formador humano.

É possível afirmar que o gênero épico abarca obras didáticas por excelência, em cujos heróis, Aquiles e Ulisses, por exemplo, destacam-se um conjunto das virtudes humanas e normas de conduta que serviam de modelo para os gregos e pilares constituintes de toda uma cultura helênica, de modo que, não sem razão de ser, Homero foi chamado de "educador de seu povo" (JAEGER, 2003, p. 61).

A poesia, pelo menos na Antiguidade grega, é um fenômeno estruturador da cultura, ou melhor, poesia coincide com cultura, no sentido de educação e civilização. Os

\footnotetext{
2 Cf. TREVIZAM, 2014, p. 20.
} 
textos de Homero são relatos que instituem práticas e determinam modos de viver e pensar que constituirão o núcleo daquilo que chamaremos "cultura grega" (SOUZA, 2007, p. 196).

Para os romanos, esse elo da poesia com a educação não poderia ser diferente, já que assíduos seguidores e discípulos da cultura literária grega. Desde sempre, a poesia latina também não dissociou potenciais estéticos e educadores.

Em suma, o caráter didático e o funcionamento normativo podem constituir todo e qualquer texto. Entretanto, em termos literários, para garantir a pertinência ao gênero especificamente didático de poesia, é necessário que as obras ostentem parâmetros e moldes específicos, dentre os quais podemos destacar, primeiramente, a disposição em versos.

Esse tipo textual prescinde também da postura de ensinamento de um magister dirigindose aos discipuli, criando um ambiente, ainda que ficcional, de aula. Deve existir uma voz que emana do texto tratando de uma determinada matéria destinada a um receptor.

Outra característica marcante deste gênero de poesia é a evocação aos poetas antecessores que serviram de modelo literário. Assim, Virgílio, seguindo a tradição, faz menção a Hesíodo, prestando-lhe tributo. A esse respeito, comenta Dalzell que

Havia códigos literários que marcavam essa distinção genérica. O mais óbvio deles era recorrer à autoridade de Hesíodo, o "prôtos heurêtês" do gênero. Arato é louvado por Calímaco por seguir o tema e o modo de Hesíodo (Epigr. 29.1). Virgílio descreve as "Geórgicas" como o "canto de Ascra" (2.176), e suas palavras são posteriormente ecoadas por Columela (10.436). Nicandro invoca o testemunho de "Hesíodo de Ascra” perto do início de seu poema sobre serpentes venenosas. Era uma prática comum entre os poetas latinos indicar suas filiações literárias no início das obras com um aceno cordial para seus predecessores (DALZELL, 1996, pp. 21-22).

$\mathrm{Na}$ literatura latina, podemos destacar três autores cujas obras enquadram-se nos ditames da poesia didática: Lucrécio com o De rerum natura, Virgílio com as Geórgicas e Ovídio com a Ars Amatoria. Temos nestes autores e em suas obras elos genéricos comuns, além do reconhecimento unânime de Hesíodo como fundador do gênero e modelo compositivo em $O s$ trabalhos e os dias.

Um último recurso inerente à poesia didática, que constitui o foco de nossa pesquisa, é a "digressão": a elevação de assuntos de maior complexidade e de naturezas diversas, em detrimento, por vezes, da explanação e descrição de técnicas agrárias. 
Sobre o nosso poeta, o modelo literário hesiódico e o uso do recurso digressivo, afirma Trevizam que

Assim, Virgílio, tributário do poeta grego num ponto tão importante quanto a adoção do mesmo "ambiente" rural (com sua indelével aura de tradicionalismo) e, em se tratando ele de ninguém menos que o "fundador" do gênero didático, por manter traços formais como as digressões, o metro e a variação de modo e "tom" expositivos, diferencia-se do mestre ao favorecer de uma maneira jamais vista antes a dispersão ideológica dos temas abstratos (TREVIZAM, 2006, p. 155).

\section{As digressões}

No âmbito da teoria literária, a digressão pode assumir diversas denominações. Ocupamo-nos, aqui, de partes do texto das Geórgicas em que o poeta abandona temporariamente a ação instrutiva, fortemente marcada pelos pronomes e verbos em $2^{\mathrm{a}}$ pessoa, em tom jussivo, e passa a descrever temas outros, sejam eles ligados a narrativas mitológicas sejam relativos a temas diversos: filosóficos, laudatórios, existenciais.

Em uma obra esclarecedora sobre a poesia didática latina (2014), Trevizam considera essas passagens como painéis ilustrativos ou mítico-narrativos. Os relatos mitológicos costumam preencher esses painéis de modo a constituírem objetos de deleite para a imaginação. Os painéis são pausas na estrita preceituação com efeitos de variação expositiva de temas e mudança no modo discursivo, isto é, o gesto de instruir passa para o de descrever e narrar ${ }^{3}$.

Em nosso entendimento, a mudança de temas e de modos discursivos constituem recursos digressivos que, para Lausberg, definem-se como um afastamento quanto ao objeto de discurso: "Consistem no tratamento, por parte do enunciador, de outra matéria em vez da matéria propriamente dita” (LAUSBERG, 1965, p. 254).

O sujeito enunciador ausenta-se desta matéria propriamente dita para tratar da situação do discurso, por exemplo, o que seria uma digressão típica, ou ainda para tratar de outras matérias diversas, e nesse caso teríamos a chamada digressio excursio. A respeito desta última, de natureza diversificada, Lausberg (1965, p. 255) define como "intercalação de pensamentos narrativos, descritivos, argumentativos, ornantes e infinitizantes”.

É recorrente a consideração das passagens digressivas como elementos apenas acessórios do texto, como trechos dispensáveis por estarem "fora do assunto", e como ferramentas para

\footnotetext{
3 Cf. TREVIZAM, 2014, pp. 30-31.
} 
desfazer um momento de tensão do texto, para ornamentá-lo de alguma forma; enfim, há várias explicações para o proposto na digressão.

Parece-nos bastante esclarecedora a assertiva de Moisés:

Própria do discurso oratório, a digressão pode apresentar qualquer medida, aparecer em qualquer parte do texto e em obras de qualquer outra natureza, sobretudo a poesia épica, o romance e o ensaio. Empregada desde a Antiguidade greco-latina, constitui expediente difícil de manejar, uma vez que pode comprometer a integridade da obra em que se insere. Por isso, hoje em dia tende a ostentar sentido pejorativo, equivalente a “desvio", “divagação”, "subterfúgio” (MOISÉS, 2002, p. 125).

Como não poderia ser diferente, nas Geórgicas, o artifício da digressão também gera controvérsias quanto à finalidade. De um modo geral, entende-se que, ao ingressar por outros caminhos, fugindo da temática original, o poeta abandone por completo a função instrutiva do texto, suspendendo-a momentaneamente, dando relevância a outros domínios.

Sistematicamente, considerou-se que as digressões figuram nas Geórgicas por elas mesmas, não possuindo nada de didático. Atualmente, todavia, procura-se observar que, ainda que estas passagens não veiculem preceituação técnica e científica, veiculam discursos atrelados a outros domínios, como dissemos, que um sujeito enunciador transmite ao enunciatário (leitor/aluno), buscando produzir efeitos de sentido.

$\mathrm{Na}$ obra, as digressões encontram-se assim divididas nos versos, conforme apresenta Otis ${ }^{4}$ :

\section{LIVRO I: Cereais}

118 a 159: A justificativa religiosa do trabalho.

424 a 514: O sol como o profeta da destruição: Os presságios da morte de César; as más condições de Roma.

\section{LIVRO II: Plantas}

136 a 176: Os elogios à Itália.

315 a 345: Os elogios à primavera.

458 a 540: Os elogios à vida agreste.

\section{LIVRO III: Animais}

209 a 283: O Amor.

\footnotetext{
${ }_{4}^{4}$ Cf. OTIS, 1963, pp. 148-151.
} 
470 a 566: A peste.

\section{LIVRO IV: Abelhas}

116 a 148: O velho de Tarento.

315 a 558: O mito da ressurreição.

Uma vez que a poesia, sobretudo a didática, é capaz de transmitir costumes, tradições, valores, crenças, rituais, normas de conduta, enfim, modos de viver e de pensar, indagamo-nos de que maneira as Geórgicas, um poema essencialmente agrícola que ensina métodos racionais de cultura, podem estar a serviço de amplas reflexões sobre temas filosóficos teológicos e políticos?

A respeito da importância das digressões, são pertinentes os seguintes questionamentos de Gale (2000, p. 1): "O poema é realmente sobre agricultura? O que mais, se houver, o poeta tenta ensinar? Qual a relação entre as passagens de instrução agrícola e as assim chamadas digressões 5 ?"

\section{As condições de produção}

Lembrando brevemente o contexto de produção da obra, escrita entre 37 e 30 a. C., período compreendido entre a Batalha de Filipos (42 a. C.) e a de Ácio (31 a. C.), vale esclarecer que é nesta fase da história de Roma que, a exemplo do que ocorrera em épocas anteriores, significativas transformações sociopolíticas passam a acontecer, especificamente a partir da segunda metade do I século a. C., depois da morte de Júlio César. As contendas agrárias estão em voga, sobretudo no que tange à destruição do campo pelas guerras civis e às expropriações de grandes e pequenos agricultores como parte do programa de reassentamento dos veteranos. É mister refletir sobre o empobrecimento da população numa Roma devastada pelas guerras.

Nesse sentido, não poderíamos pensar nas Geórgicas como uma obra desprovida de conteúdo sociopolítico, num poema didático tão somente sobre terra, árvores, gado e abelhas. Há que se destacar uma latente preocupação do estreitar de laços entre a poesia e os valores tradicionais romanos. Podemos afirmar que Virgílio segue os caminhos de Hesíodo na medida em que percebe a poesia didática como um veículo por excelência para a transmissão de ideais morais religiosos e filosóficos 6 .

\footnotetext{
5 'Is the poem 'really' about agriculture? What, if anything, is the poet trying to teach? What is the relationship between the passages of agricultural instruction and the so-called digressions?” (In: GALE, 2000, p. 1)

${ }^{6}$ Cf. WEEDA, 2015, p. 86.
} 
Os próprios versos nos fornecem indícios de que haveria uma mensagem "diferente" e que o poeta não se inclina a compor um simples manual de agricultura, mesclando assuntos diversos ao tema dos campos:

non ego cuncta meis amplecti uersibus opto, non, mihi si linguae centum sint oraque centum, ferrea uox (VIRG. Geo. II, vv. 42-44).

Não desejo abranger todas as coisas juntas em meus versos, não conseguiria, ainda que possuísse cem línguas e cem bocas, e uma voz de ferro?

Verum haec ipse equidem spatiis exclusus iniquis praetereo atque aliis post me memoranda relinquo (VIRG. Geo. IV, vv. 147-148).

Mas, na verdade, eu mesmo, impedido pelos pequenos espaços, ponho de lado estas coisas e deixo-as aos outros para que sejam relembradas depois de mim.

Notamos, aqui, o desejo pela brevidade não demonstrando nenhuma intenção de que sua obra seja completa, pois talvez o que importe, de fato, seja outra mensagem.

\section{O canto II das Geórgicas}

De acordo com Gale (2000, pp. 18-19), há um equilíbrio elegante na estruturação dos cantos e o exemplo desta padronização está nos proêmios e conclusões dos quatro cantos que lidam com imagens alternadas (nascimento x morte / crescimento x decadência): os cantos 1 e 3 são considerados dark books, aqueles que tratam de temas densos e sombrios como o fim da Idade de Ouro, guerras, mortes e doenças que assolam homens e animais igualmente. Já os cantos 2 e 4 são mais leves quanto ao "humor"8. O 4 trata especificamente da sociedade das abelhas, estruturada na cooperação através do trabalho, as quais não são acometidas e nem fadadas às desilusões amargas do amor e da doença.

O segundo canto apresenta a convivência harmônica entre agricultor e natureza, numa vida alheia às preocupações militares e políticas. É, talvez, no conjunto da obra, o canto mais epicurista, na medida em que aborda o desapego ao luxo e às riquezas materiais e a valorização, por outro lado, da vida simples e virtuosa que só o campo pode proporcionar.

\footnotetext{
7 Todas as traduções são de responsabilidade da autora deste artigo.

8 Cf. GALE, 2000, pp.18-19.
} 
São postos em evidência os três eixos basilares do fazer agrícola: a terra (tellus), sua fertilidade (uer) e o trabalhador rural (agricola). Temos, em especial, a descrição da exuberância das terras italianas, sua incessante fertilidade favorecida, principalmente, pela primavera constante, e o agente da produção, o homem do campo, aquele que, em contato direto com a terra, executa o trabalho árduo de manipulação, plantio e colheita.

Tais elementos e sua relevância nesse contexto didático-agrícola são reiteradamente apresentados ao longo de todo o poema, porém, aqui, são elevados ao status de protagonistas do canto, laudatoriamente retratados em cada uma das três digressões, as quais constituem um verdadeiro panegírico, e em cujo discurso manifesta-se um orgulhoso patriotismo expresso nas descrições relativas à qualidade da terra e ao valor de seu povo.

O tema central do canto II das Geórgicas é a arboricultura, o cultivo dos vegetais, em especial da vinha e da oliveira. Nele, são ensinadas as técnicas aplicadas ao plantio e ao crescimento dos vegetais, as distinções entre as várias espécies e a melhor distribuição geográfica, observando os diferentes tipos de solo etc.

Como é costume no início de cada livro, o poeta alude a uma divindade específica associada à atividade rural em questão. Nos primeiros versos, destaca-se um entusiasmado hino de louvor a $\mathrm{Baco}^{9}$ - divindade romana associada ao vinho e que preside o culto da videira entusiasmo que vai "permear" todo esse livro II.

Os tons obscuros do final do livro I, relativos à violência das guerras civis, agora cedem lugar a um novo recomeço. Baco é invocado como o deus do plantio e da fertilidade e, benevolentemente, oferece seus presentes aos seus adoradores ${ }^{10}$.

Observemos o proêmio:

Hactenus aruorum cultus et sidera caeli:

nunc te, Bacche, canam, nec non siluestria tecum

uirgulta et prolem tarde crescentis olinae.

huc, pater o Lenaee (tuis hic omnia plena

\footnotetext{
9 Uma das vertentes da lenda de Baco narra que ele era filho de Júpiter e Sêmele. Esta morre instantaneamente por ser incapaz de suportar a visão dos relâmpagos que rodeavam o pai dos deuses. Por Sêmele estar no sexto mês de gestação, Júpiter arranca-lhe a criança do ventre e coloca-a em sua própria coxa para que o período seja concluído. Ao final desse tempo, Júpiter retira Baco completamente formado e vivo. A partir de então, este inicia suas peripécias para fugir da perseguição da ciumenta esposa de seu pai, Juno que, não tendo conseguido eliminá-lo nas entranhas maternas e no berço, enlouqueceu-o. Deste mal foi curado por Cibele, que o purificou e iniciou nos ritos de seu culto. Tornando-se adulto, foi um grande auxiliar do pai na guerra dos deuses contra os gigantes. Líber e Leneu também eram nomes latinos de Baco (referência?).
}

${ }^{10}$ Cf. GALE, 2000, p. 36. 
muneribus; tibi pampineo grauidus autumno

floret ager, spumat plenis uindemia labris),

huc, pater Lenaee, ueni nudataque musto

tinge nouo mecum decreptis crura coturnis (VIRG. Geo. II, vv. 1-8)

Até agora, o cultivo das árvores e os astros celestes: agora, Baco, (eu) te cantarei, e também contigo as moitas silvestres e a prole da oliveira que cresce vagarosamente. Vem para cá, ó Pai Leneu, (aqui todas as coisas estão repletas com os teus presentes; o campo carregado com o pâmpano de outono floresce para ti, a vindima espuma com as bordas cheias). Vem para cá, ó Pai Leneu, e, tirados os coturnos, mergulha comigo as pernas nuas no novo vinho doce.

Os primeiros versos funcionam como elementos coesivos que articulam os temas abordados anteriormente aos que serão tratados a partir de então, demonstrando um fio condutor que organiza a apresentação da matéria agrícola. Confrontam-se passado e presente, como podemos observar pelo uso dos advérbios hactenus no verso 1, onde o hexâmetro dispensa a forma verbal subentendida cecini, e nunc (v. 2), ambos em destaque na posição inicial dos versos, marcando, como é muito próprio de uma produção didática, a organização temporal, o antes e o agora, o que já foi tratado e o que está por vir.

O louvor à divindade é explicitado na forma verbal canam (v. canere), em destaque na posição central do verso. É interessante comentar que esse verbo possui um valor semântico aproximado ao do verbo latino canto (v. cantare), seu frequentativo, que dá ideia de continuidade, frequência. Os dois verbos, contudo, distinguem-se pelo fato de o verbo cano, utilizado repetidas vezes ao longo do poema, significar não só "cantar" em sentido estrito, mas também, e principalmente em se tratando de entes sobrenaturais, "celebrar”, "anunciar”, "louvar".

É possível compreender esta passagem como uma prece11, cujo destinatário é explicitado pelos vocativos Bacche (v. 2) e pater Lenaee (vv. 4 e 7). O direcionamento da prece também é apresentado por meio das formas pronominais em $2^{\mathrm{a}}$ pessoa do singular, te e tecum (v. 2), tuis (v. 4), tibi (v. 5), e com os imperativos ueni (v. 7) e tinge (v. 8), produzindo um sentido dialógico de convocação da presença do deus. Além dele, serão cantadas as moitas silvestres e a prole da oliveira (vv. 2-3), que aparecem também como complementos verbais da forma canam.

As imagens apresentadas nestes versos configuram a reciprocidade na relação direta entre a divindade e a própria natureza. Todas as coisas estão cheias (omnia plena, v. 4) com os presentes

\footnotetext{
11 Prece esta que rememora aquelas que, em geral, iniciam um poema épico.
} 
de Baco, o campo carregado (ager grauidus, v. 5-6) floresce em honra ao deus. Este, por sua vez, favorece a vindima gerando bordas cheias.

O advérbio hic (v. 4), reforçado pelo advérbio huc, repetido nos versos 4 e 7 , faz clara referência ao local em que se dá a cena pintada pelo poeta, transportando-nos, como salienta Mayer (1948, p. 254), a um campo colorido, indicado pelo próprio verbo floret (v. 6), com as tonalidades variadas das uvas e das parreiras, e, completando o quadro, a imagem de um lagar rústico em que o mosto novo espuma e onde prossegue o trabalho da pisa, que o Deus é convidado a acompanhar ${ }^{12}$.

Terminada a prece, o poeta retoma seus assuntos práticos acerca da variedade da reprodução das árvores na natureza, dos aspectos relativos ao crescimento das plantas, e sua distribuição geográfica. Descreve os tipos de árvores e os tipos de solo, explicando que vegetação é adequada para cada terra, narra onde nascem os salgueiros, as murtas, olmeiros, as vergônteas... E com que "tipo" de sol eles crescem. Passa, então, a enumerar lugares, cada qual com sua vegetação específica: as moradas orientais dos Árabes, a Índia, o solo dos sabeus.

Em seguida, o poeta nos apresenta diversos produtos exóticos colhidos em terras exóticas, elevando o tom para um primeiro clímax do livro, que não só complementa o tema da variedade, mas também dá a ela um local, um lar: a Itália supera tudo aquilo que é exótico ou peculiar. É quando se inicia, no verso 136, a primeira digressão da Geórgica II.

\section{Laudes Italiae}

Descortina-se uma premissa inicial categórica: a de que nenhuma terra, por mais rica que seja, pode superar a Itália em motivos de louvores e glórias, sendo posta em destaque como a melhor dentre todas as outras em atributos, uma terra perfeita, produtora de frutas e vinho, de ovelha e gado, lar de notáveis cidades, extraordinários lagos e rios e, sobretudo, mãe de uma raça indomável de homens.

O conteúdo desta digressão aponta para possíveis engajamentos ideológicos, próprios das condições de produção da obra. Neste sentido, é possível verificar um conteúdo claramente "patriótico" já assumido nestes versos iniciais: tal exaltação da pátria sugere um comprometimento da obra com a política de reconstrução e de retomada dos antigos valores romanos, bem como de restauração da antiga agricultura romana, buscada no tempo de Virgílio.

\footnotetext{
12 Cf. MAYER: 1948, p. 254.
} 
Sed neque Medorum siluae, ditissima terra, nec pulcher Ganges atque auro turbidus Hermus laudibus Italiae certent, non Bactra neque Indi totaque turiferis Panchaia pinguis harenis (VIRG. Geo. II, vv. 136 - 139).

Mas nem as florestas dos Partos, terra riquíssima, nem o belo Ganges e nem o Hermo agitado pelo ouro rivalizam com a Itália em glórias, nem os Bactras, nem os Indos e toda a Pancaia rica em areias que produzem incenso.

Cada uma das localidades mencionadas é qualificada, como podemos observar, por meio dos adjetivos ditissima (v. 136) e pulcher (v. 137), sendo o primeiro mais enfático, por encontrar-se no superlativo. Isto significa que não se trata de qualquer lugar, mas de terras belas, ricas e que também produzem objetos valiosos como ouro e incenso. A Itália, todavia, as supera, seja em riquezas geográficas, seja em valor demográfico:

haec loca non tauri spirantes naribus ignem inuertere satis immanis dentibus hydri, nec galeis densisque uirum seges horruit hastis (VIRG. Geo. II, vv. 140 - 142).

Os touros que sopram fogo pelas narinas não modificaram estes lugares o suficiente com os dentes da terrível hidra, e a seara não temeu homem com capacetes e lanças densas (...)

A segurança também é um recurso valioso: nem os animais ferozes devem ser temidos, os touros e as hidras, os raivosos tigres e leões, e a enorme serpente contorcendo suas dobras escamosas pelo chão, tampouco as tormentas da guerra, representadas, no texto, pela imagem construída do homem de capacetes e lanças densas. Uma ausência que remeteria mais uma vez aos anseios por tempos de paz, que seriam alcançados através da figura de Augusto.

Vale comentar brevemente uma alusão mitológica grega quando mencionados os touros que sopram fogo pelas narinas e os dentes da terrível hidra. De acordo com a lenda, Jasão teria sido obrigado a lavrar um campo, dominando bois deste tipo, e depois semeá-lo com os dentes de dragão. Segundo Mayer, Virgílio estaria ironizando esta agricultura fantástica, fruto dos excessos da imaginação grega, em contraposição à realidade tranquila dos campos italianos ${ }^{13}$.

\footnotetext{
13 MAYER, 1948, p. 277.
} 
Quanto à terra, nela, a fecundidade está sempre presente tanto relativamente às plantas, que sempre se encontram repletas de pesados frutos (v. 143), quanto aos animais (v. 144).

sed grauidae fruges et Bacchi Massicus umor

impleuere; tenent oleae armentaque laeta (VIRG. Geo. II, vv. 143 - 144).

(...) mas a encheram frutos pesados e o vinho mássico de Baco; ocupam-na oliveiras e férteis rebanhos.

hic uer adsiduum atque alienis mensibus aestas:

bis grauidae pecudes, bis pomis utilis arbos (VIRG. Geo. II, vv. 149 - 150).

Aqui, a primavera é permanente e o calor perdura durante outros meses: os gados tornam-se férteis duas vezes, e duas vezes a árvore é útil para os frutos.

Esta fertilidade permanente da fauna e da flora é reiterada ainda no verso 150 e é também representada pela primavera, estação do ano que simboliza a fertilidade (uer adsiduum - a primavera permanente - v. 149) e que é tratada não só por Virgílio, mas pelos autores antigos em geral, como a época mais propícia para o amor, para a fertilidade e para o nascimento de todas as coisas, afinal o mundo teria nascido na primavera (uere natus orbis est $t^{14}$ ). Para exemplificar, cabe lembrar outra referência à força da primavera encontrada na digressão sobre o amor, que consta no canto III das Geórgicas. O poeta, ao explicar de que forma o amor domina todas as raças, seja de homens seja de animais, anuncia:

Continuoque auidis ubi subdita flamma medullis

(uere magis, quia uere calor redit ossibus) (VIRG. Geo. III, vv. 271 - 272).

E, assim que a chama entrou nas suas ávidas medulas, (sobretudo na primavera, porque é na primavera que o calor volta aos ossos).

Até este ponto, os sentidos são construídos a partir de exemplos e da enumeração de elementos, com vistas à caracterização da Itália: beleza, segurança, paz, ausência de feras e guerras e, sobretudo, a frequente fertilidade da terra e dos animais.

\footnotetext{
14 Peruigilium Veneris, v. 2, apud NOVAK \& NERI, 2003, p. 250.
} 
Nos versos v. 145-148, demonstra-se uma preocupação com o cumprimento de rituais consagrados às divindades, dos quais derivam os triunfos romanos.

hinc bellator equus campo sese arduus infert, hinc albi, Clitumne, greges et maxima taurus uictima, saepe tuo perfusi flumine sacro, Romanos ad templa deum duxere triumphos (VIRG. Geo. II, vv. 145 - 148).

Daqui o rápido cavalo guerreiro lança-se ao campo de batalha, daqui, Clitumno, os brancos rebanhos e o touro, vítima principal, banhados no teu rio sagrado, frequentemente conduziram os triunfos romanos até os templos dos deuses.

Há que se notar a sistemática presença do divino, dos entes superiores, na trama das Geórgicas. Em diversos trechos, podemos encontrar narrativas mitológicas ou simples alusões a deuses, que, por vezes, presidem determinadas atividades agrícolas ou associam-se a elementos da natureza, e aos cultos religiosos que lhes são atribuídos. Lembremo-nos do próprio conselho de Virgílio: in primis uenerare deos ${ }^{15}$.

A partir do verso 155, são exaltadas as construções erigidas na adversidade do relevo das cidades pela destreza do trabalho humano, o exímio labor, que transpõe obstáculos como rochedos e rios. Em seguida, são descritos o terreno e a localização destas edificações, nas proximidades do mar, de rios, lagos, montes e outros acidentes geográficos da região italiana, delineando um grande panorama do poder inerente à própria terra:

adde tot egregias urbes operumque laborem, tot congesta manu praeruptis oppida saxis fluminaque antiquos subter labentia muros. an mare quod supra memorem, quodque adluit infra? anne lacus tantos? te, Lari maxime, teque, fluctibus et fremitu adsurgens Benace marino? an memorem portus Lucrinoque addita claustra atque indignatum magnis stridoribus aequor, Iulia qua ponto longe sonat unda refuso Tyrrhenusque fretis immittitur aestus Auernis? haec eadem argenti riuos aerisque metalla ostendit uenis atque auro plurima fluxit (VIRG. Geo. II, vv. 155 - 166).

Acrescente tantas notáveis cidades e o trabalho das obras, tantas fortalezas erigidas pela mão (do homem) em rochedos abruptos, e os rios que escoam por debaixo das antigas

\footnotetext{
15 VIRG. Geo. I, v. 338.
} 
muralhas. Acaso eu recordarei o mar que banha acima e abaixo? E tantos lagos? E tu, grande Lario, e tu Benaco, que te levantas com ondas e um rugido do mar? Acaso eu recordarei os portos e as muralhas colocadas junto de Lucrino e o mar indignado pelos grandes ruídos, por onde a onda Júlia ressoa ao longe no mar que transborda e a agitação do mar Tirreno precipita-se no orgulhoso Averno? E esta mesma (Itália) mostrou em suas veias rios de prata e minas de bronze e escorreu (pelos rios) uma grande quantidade em ouro.

Em seguida, são citados povos notáveis pelas glórias e pela força como os marsos e sabelos, volscos e lígures. Mayer, nas notas de sua tradução das Geórgicas, assim descreve os povos:

"Os Marsos foram alternadamente excelentes aliados e perigosos inimigos dos romanos. Dizia-se que era impossível vencê-los. Sabelos são os povos de raça Sabina e os Ligures são os habitantes da região acidentada que contorna o Golfo de Gênova. Os Volscos eram destros no manejo do veru, lança curta de um metro de comprimento" (MAYER, 1948, p. 279).

haec genus acre uirum, Marsos pubemque Sabellam

adsuetumque malo Ligurem Volscosque uerutos

extulit, haec Decios Marios magnosque Camillos,

Scipiadas duros bello et te, maxime Caesar,

qui nunc extremis Asiae iam uictor in oris

imbellem auertis Romanis arcibus Indum (VIRG. Geo. II, vv. 167 - 172).

Esta gerou uma raça indomável de homens, os marsos e a mocidade Sabina, e o lígure habituado à vida penosa e os volscos armados com dardos. Esta gerou os Décios, os Mários e os grandes Camilos, os Cipiões endurecidos pela guerra e tu, grande César, que agora já vitorioso nos confins da Ásia, repeles o Indo pacífico das afastadas cidadelas romanas.

A ordem em que os povos são citados nos parece cuidadosamente escolhida: primeiro as tribos italianas e, em seguida, a partir do verso 170, os grandes guerreiros romanos, apresentados no plural, os Décios, Mários, Camilos e Cipiões (vv. 169-70), embora, conforme Putnam ${ }^{16}$, nossa mente possa remeter a apenas um indivíduo dentro de cada grupo.

Depois de elencar toda a genus acre uirum (v. 167), a longa linhagem de guerreiros converge na direção do maior herói de todos, maxime Caesar (v. 170). Putnam (apud VOLK,

16 Apud VOLK, 2008, p. 142. 
2008, p. 142) comenta essa passagem nos seguintes termos: "Então esses heróis romanos em duplicatas agora dão lugar ao império e à autocracia do mais poderoso de todos, o qual absorve nele mesmo a maior força da Itália e dos senhores passados de Roma ${ }^{17}$ ".

São lembrados os grandes e bravos homens de guerra oriundos destas terras, apontando assim sua maior riqueza: a demográfica. E também César, Otávio, que vitorioso se juntava a tão nobres romanos. Esta rica região, que produziu sua raça de homens em tão opulento cenário, é a Saturnia tellus. Ao saudá-la, o poeta faz reviver a Idade de Ouro, quando Saturno reinava e os homens desconheciam penas, misérias, velhices, todos os males, sustentados pela abundância voluntária da terra.

A matéria didática construída ao longo dos versos desta primeira digressão é elencada na apóstrofe final, em que o poeta, interrompendo o discurso essencialmente descritivo, dirige-se à própria terra saudando-a como grande mãe de frutos, terra de Saturno, grande mãe de homens (vv. $174-5)$.

salue, magna parens frugum, Saturnia tellus, magna uirum: tibi res antiquae laudis et artem ingredior sanctos ausus recludere fontis, Ascraeumque cano Romana per oppida carmen (VIRG. Geo. II, vv. 173 - 176).

Salve, grande mãe de frutos, terra de Saturno, grande mãe de homens: para ti começo a desvendar coisas da antiga honra e arte e, ousando desvendar as fontes sagradas, canto um verso ascreu pelas cidades romanas.

Virgílio propõe-se a revelar os segredos da antiga glória e arte: a agricultura. Ele expõe as fontes sagradas da poesia, observando que está a produzir um cântico ascreu, isto é, de Ascra, na Beócia, terra natal de Hesíodo. A Itália é a terra que a natureza fez mais fértil e bela, e, por sua história e pelo valor de seus habitantes, tornou-se a mais gloriosa.

Neste final, evidencia-se o caráter do poema, mergulhado nas antigas raízes e sagradas tradições da Itália: destina-se a exaltar o povo romano, cujo espírito é extremamente patriótico inspirando-se, contudo, em moldes gregos.

O tema da variedade e espontaneidade da natureza associadas à resiliente e feliz cooperação humana está estreitamente ligado a dois outros temas recorrentes na obra virgiliana: a Idade de Ouro e a natureza exuberante da Itália, que é a própria Saturnia tellus, na qual a

\footnotetext{
${ }^{17}$ So these heroic Roman doublings now give place to empire and to the autocracy of the mightiest of all, who absorbs in himself the broad strength of Italy and of her past Roman overlords (In: VOLK, 2008, p. 142).
} 
primavera é contínua, a fertilidade é incessante e o perigo das feras está ausente. O homem, por sua vez, completa essa atmosfera, sendo visto não mais como um lutador que resiste ao meio ambiente na luta pela sua própria sobrevivência.

\section{Considerações finais}

É interessante notar, como bem destaca Otis, que esta passagem que constitui um deliberado contraste com a áspera imagem da Idade de Ferro, localizada quase exatamente na porção correspondente do livro I (v. 118-159), representa o "outro lado da moeda", a união entre o homem e o campo, entre natureza e civilização, entre mito e História de Roma, entre inocência e segurança que devem estar contra a luta amarga e a tensão que dominam o livro precedente (OTIS, 1963, p. 164).

A restauração da terra e da paz, entretanto, só poderia se dar por meio da estabilidade conquistada a partir da força militar. Esta passagem que, por um lado, elogia a Itália como uma terra rica e fértil, por outro, refere-se a ela como tendo gerado genus acre uirum - duas faces, assim, de uma mesma moeda: guerra e paz. O espírito romano precisava ser exaltado, para que então fosse reafirmado o prestígio e a majestade da Itália perante os outros lugares. A paz perdida outrora com o fim da Idade de Ouro estava retornando, a pax romana estava sendo estabelecida por Augusto.

Por fim, julgamos importante destacar que, em nosso entendimento, as narrativas míticas, fábulas e elogios diversos não funcionam tão somente como partes alegóricas do texto, mas, ao contrário, compartilham do objetivo principal da poesia didática, o de instruir, ainda que sob moldes discursivos diferentes.

Nas Geórgicas, uma digressão pode ilustrar com imagens um determinado momento em que a abordagem do tema rural parece exaurir-se e expor temas outros calcados em conceitos universais, de fundamental importância não apenas para o imaginário da sociedade romana antiga, como também do interesse das sociedades de qualquer época.

As considerações sobre valores éticos, morais, bem como as reflexões acerca da existência, fé, trabalho, esforço, persistência, bravura, recompensa e mérito enriquecem a obra no nível semântico, demandando atenção para o fato de que o sentido geral e uno da obra não se resume a uma simples transmissão de ensinamentos agronômicos. 


\section{Referências bibliográficas:}

\section{Fontes primárias:}

HESÍODO. Os trabalhos e os dias. Introdução, tradução e comentários Mary de Camargo Neves Lafer. São Paulo: Ed. Iluminuras, 1996.

VIRGILE. Georgiques. Texte établi et traduit par E. de Saint- Denis. Paris: Les Belles Lettres, 1968.

\section{Fontes secundárias:}

DALZELL, A. The criticism of didactic poetry. Essays on Lucretius, Vergil and Ovid. Toronto; Buffalo; London: University of Toronto Press, 1996.

GALE, M. "Virgil on the nature of things", In: The Georgics, Lucretius and the didactic tradition. Cambridge: Cambridge University Press, 2000.

JAEGER, W. Paideia - a formação do homem grego. Trad. Artur M. Parreira. São Paulo: Martins Fontes, 2003.

LAFER, Mary de Camargo Neves. "Introdução", In: HESÍODO. Os trabalhos e os dias. Introdução, tradução e comentários Mary de Camargo Neves Lafer. São Paulo: Iluminuras, 1996.

LAUSBERG, H. Elementos de retórica literária. Lisboa: Fundação Calouste Gulbenkian, 1965. . Handbook of literary rhetoric: a foundation for literary study. Transl. by Matthew T. Bliss. Leiden; Boston; Köln; Brill, 1998.

MAYER, Ruy. "Introdução”, In: VIRGÍLIO. As Geórgicas de Virgílio. Versão em prosa dos três primeiros livros e comentários de um agrônomo. Lisboa: Livraria Sá da Costa, 1948.

MOISÉS, Massaud. Dicionário de termos literários. 12. ed. São Paulo: Cultrix, 2003.

NOVAK, Maria da Gloria \& NERI, Maria Luiza (Orgs.). Poesia lírica latina. Campinas: Martins Fontes, 2003.

OTIS, Brooks. Virgil: a study in civilized poetry. Oxford: Oxford University Press, 1963.

SANTOS, Elaine C. Prado dos. O IV canto das Geórgicas. São Paulo: Scortecci, 2007. . O IV canto no contexto das Geórgicas, tradução e notas. Dissertação de Mestrado. São Paulo: USP, 1995.

SOUZA, Jovelina M. R. de. “A poesia grega como paidéia”, In: Princípios. Natal, v. 14, n. 21, Jan / Jun, 2007; p. $195-213$.

TREVIZAM, Matheus. Linguagem e interpretação na literatura agrária latina. Tese de Doutoramento. Campinas: UNICAMP, 2006. 
. Poesia didática: Virgílio, Ovídio e Lucrécio. Campinas: Editora da UNICAMP, 2014.

VOLK, Katharina. Oxford readings in Classical studies: Vergil's Georgics. Oxford: Oxford University Press, 2008.

- The poetics of Latin didatic: Lucretius, Vergil, Ovid, Manilius. Oxford: Oxford University Press, 2008.

WEEDA, Leendert. Vergil's Political Commentary in the Eclogues, Georgics and Aeneid. Berlin: De Gruyter Open, 2015. 